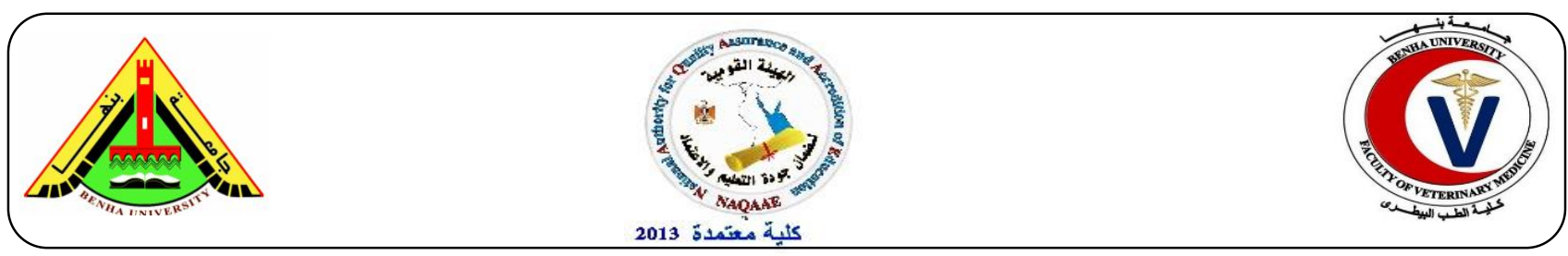

\title{
A Potent Antioxidants Property of Moringa Oleifera on Mycotoxin Induced Oxidative Stress in Rats
}

\author{
Hussein S.A. ${ }^{*}$; Abd el-hamid O.M. ${ }^{1}$; El-tawil O.S. ${ }^{2}$ Laz E.S. $^{3}$ and Taha W.M. ${ }^{3}$
}

${ }^{1}$ Department of Biochemistry, Faculty of Vet. Med., Benha University, Egypt.

${ }^{2}$ Department of Toxicology and Forensic Med., Faculty of Vet. Med., Cairo University, Egypt.

${ }^{3}$ Department of Biochemistry and food deficiency, Animal Health Research Institute, Dokki, Giza, Egypt.

*Corresponding author: Samy Ali Hussein; email: samyaziza@yahoo.comsamy.aziza@Futm.bu.edu.eg

\section{A B S T R A C T}

This work aimed to evaluate the probable protective effect of Moringa Oleifera on mycotoxins induced liver damage and oxidative stress in rats. Thirty male albino rats were classified randomly into three equal groups. Group1 (normal control): Rats fed with ordinary ration. Group2(Mycotoxin): Rats fed with ordinary diet only for first 7 days and from day 8 rats fed mixed ration contain 50 gram of grinded plant (total aflatoxins $4.2 \mathrm{ppb}$ ) +50 gram of grinded fish (total aflatoxins $42.14 \mathrm{ppb}$ ) +50 gram of ordinary diet (free of aflatoxins) for 4 weeks. Group3 (Mycotoxin+ Moringa): Moringa Oleifera (350 mg/kg b.w) was administered orally allover the experimental period (5 weeks). Also, rats were fed with ordinary ration only for first 7 days and from day 8 rats fed mixed ration that mentioned above in group 2. At the end of the experiment liver tissue specimens were isolated and analyzed for the determination of reduced Glutathione (GSH), superoxide dismutase (SOD), catalase (CAT), L-malondialdehyde (L-MDA) and tumor necrosis factor-alpha (TNF- $\alpha$ ) gene expression. The obtained results showed a significant up-regulation of TNF- $\alpha$ gene expression level and marked increase in hepatic SOD, CAT activities and L-MDA of mycotoxin rats group. However, liver GSH concentration was markedly decreased as compared to control group. Moringa protected mycotoxins induced liver damage in rats caused a significant improvement of all previous parameters. Conclusively, Moringa Oleifera treatment exerts a protective effect against liver damage and oxidative stress in liver of mycotoxin intoxicated rats through free radical scavenging and antiinflammatory activities as well as regenerating endogenous antioxidants defense system mechanisms.

Key words: Mycotoxins, TNF- $\alpha$, oxidative stress, Moringa Oleifera.

(http://www.bvmj.bu.edu.eg)

(BVMJ-35(2): 384-392, 2018)

\section{INTRODUCTION}

The term mycotoxin was coined in 1962 in the aftermath of an unusual veterinary crisis near London, England, during which approximately 100,000 turkey poults died
(Blout, 1961). Mycotoxins are mainly produced by fungi in the Aspergillus, Penicillium, Fusarium (Overy et al., 2003). The contamination of foods by the major 
mycotoxins, e.g. aflatoxins B1 (AFB1), aflatoxins B2 (AFB2), aflatoxins G1 (AFG1), aflatoxins G2 (AFG2), ochratoxin A (OTA), fumonisins (FB1 and FB2), deoxynivalenol (DON), T-2, HT-2, and zearalenone (ZEA), has been recognized by the World Health Organization (WHO, 2002) as a significant source of food-borne illnesses which induce a lot of injuries in different organs and tissues, immune-suppression, deteriorates lipid, carbohydrate and protein metabolism, decreases in growth rate and increases in death rate for human and animals, which lead to serious economic losses (Dönmez et al., 2012).

Oxidative stress might be induced by generating the intracellular reactive oxygen species (ROSs) during metabolic process of AFB1 in liver. These radicals can bind with DNA constituents and attack the other endogenous biological components such lipid and protein causing DNA damage, genotoxicity and impairment the different metabolic pathways in the living cells and consequently lead to genomic instability including the alteration of genes (Yang et al.,_2016). Meanwhile, metabolism of mycotoxins in liver play a dangerous role in production of free radicals, lipid peroxidation and cell damage (Dönmez et al., 2012). Although AFB1 had been found to be a main carcinogen for implicating in hepatocellular carcinoma, kidney damage in affected areas has revealed its presence in a lot of cases (Darwish et al., 2011). Moreover, severe aflatoxicosis involves haemorrhagic necrosis of liver, edema, bile duct proliferation and lethargy that give rise to direct liver damage (Yaman et al., 2016).

Moringa oleifera is a multipurpose and rapid-growing tree which its leaves and pods are a potential source of natural antioxidants such as total phenolics, antioxidant vitamin $\mathrm{A}, \mathrm{C}$ and $\mathrm{E}$, ascorbic acid oxidase, polyphenol oxidase, catalase, $\mathrm{Ca}, \mathrm{Mg}, \mathrm{K}, \mathrm{Mn}, \mathrm{P}, \mathrm{Zn}, \mathrm{Na}$,
$\mathrm{Cu}$, and Fe (Vongsak et al., 2013). The leaves also are a rich source of flavenoids, Carotenoids, isothiocyanates, niazimicin, glucosinolates, essential amino acids such as methionine, cysteine, tryptophan, lysine, vitamins and minerals. It is rich in compounds containing the simple sugar, rhamnose and a fairly unique group of compounds called glucosinolates and isothiocyanates so this makes it a virtually ideal dietary supplement (Bennett et al., 2003).

All the parts of the Moringa tree (e.g., pods, seeds, and leaves) have long been employed for the treatment of many diseases, and therefore, it was called a "miracle vegetable", (Anwar et al., 2007). Its different parts whether in powdered form, aqueous or ethanolic extract were used for treatment of cancer (Krishnamurthy et al., 2015) and inflammation (Minaiyan et al., 2014). The constituents of niazimicin and isothiocyanates were found to have strong inhibition against cancer in different mammalian cells (Fahey et al., 2004).They were also used against intestinal worms, as skin antiseptic, anti-hyperlipidemic (Souravh et al., 2014), antimicrobial (Caceres et al., 1992), antidiabetic as well as antiduretic agent (Jaiswal et al., 2009) and (Al-Malki and El Rabey, 2015). Aqueous extract possessed reduction of genetic alterations like DNA damage and micronuclei in irradiated rats by gamma irradiation (Eshak and Osman, 2013). Accordingly, because Moringa was used as a protective or a therapeutic agent, the current study was carried out to investigate the protective effect of Moringa on mycotoxins induced oxidative stress, and liver damage of male rats.

\section{MATERIALS AND METHODS}

\subsection{Experimental animals:}

Thirty white male albino rats of 45weeks and average body weight 100-130 g were used in this study. Rats were obtained 
from Laboratory Animals Research Center, Animal health research animal institute, Dokki, Cairo. Rats were housed in separated polycarbonate cages (10 per cage) on a wellbalanced ration and fresh clean drinking water ad-libitum. Rats were kept at a constant environmental and nutritional condition throughout the whole period of experiment. All rats were left for 15 days for acclimatization before the beginning of the experiment.

\subsection{Natural medical plant:-}

\subsubsection{Moringa Oleifera}

Moringa in the form of powder was obtained from Cairo National Research Center - Dokki -Egypt.

-Preparation and Dosage of Moringa:

Moringa was freshly prepared by dissolved in distilled water and administered orally using stomach tube in a daily dose of $350 \mathrm{mg} / \mathrm{kg}$ body weight (Saalu et al., 2012).

\subsection{Experimental design:}

After acclimatization to the laboratory conditions, the animals were randomly classified into three groups (10 rats each) placed in individual cages and classified as follow:

Group 1 (control group): Rats fed with ordinary ration (free of mycotoxin) only without any treatment during the entire experimental period of 5 weeks.

Group 2_(Mycotoxin group):Rats fed with ordinary ration only for first 7 days and from day 8 rats fed mixed ration contain 50 gram of grinded plant (total aflatoxins $4.2 \mathrm{ppb})+50$ gram of grinded fish (total aflatoxins 42.14 $\mathrm{ppb})+50$ gram of ordinary ration (free of aflatoxins) for 4 weeks.

Group 3 (mycotoxin + Moringa group): Moringa Oleifera (350 mg/kg b.wt/day) was administered orally allover the periods of experiment (5 weeks). Also, rats fed with ordinary ration only for first 7 days and from day 8 rats fed mixed ration contain 50 gram of grinded plant (total aflatoxins $4.2 \mathrm{ppb})+50$ gram of grinded fish (total aflatoxins 42.14 $\mathrm{ppb})+50$ gram of ordinary ration (free of aflatoxins) for 4 weeks.

2.4. Sampling:

Liver tissue specimens were collected from all animal groups (control and experimental groups) once after the end of 5 weeks.

2.4.1. Tissue samples for biochemical analysis:

At the end of the experiment the rats were sacrificed under light ether anesthesia. Liver tissues were isolated immediately, weighed and then one of them was cleaned by rinsing with cold saline and stored at -20 ${ }^{\circ} \mathrm{C}$ for subsequent biochemical analysis. All liver samples were analyzed for the determination of reduced Glutathione (GSH) concentration, superoxide dismutase (SOD), catalase (CAT) activities and malondialdehyde (MDA) concentration.

2.4.1.1. Liver tissue preparation for antioxidant determination:-

Briefly, liver tissues were cut, weighed and minced into small pieces, homogenized with a glass homogenizer in 9 volume of ice-cold $0.05 \mathrm{mM}$ potassium phosphate buffer (pH7.4) to make 10\% homogenates. The homogenates were centrifuged at 6000 r.p.m for 15 minutes at 4 ${ }^{\circ} \mathrm{C}$ then the resultant supernatant were used for the determination of the following parameters: MDA, SOD and CAT.

About $0.2 \mathrm{~g}$ of liver tissues were minced into small pieces homogenized with a glass homogenizer in $0.4 \mathrm{ml}$ of $25 \%$ metaphosphoric acid (MPA), (ref. No.: 253433-4, Sigma-Aldrich, Germany), then 1.4 $\mathrm{mL}$ of distilled water was added, mixed, incubated for 1 hour and centrifuged for 10 min at 3,000 r.p.m then the clean supernatant was removed and used for determination of GSH concentration.

2.4.1.2. Liver tissue preparation for molecular analysis: 
Liver tissue were immediately excised and frozen in liquid nitrogen and then in $80^{\circ} \mathrm{C}$ until used for tumor necrosis factor alpha (TNF- $\alpha$ ) gene expression analysis by qPCR.

\subsection{Analysis:}

\subsubsection{Biochemical analysis:-}

Liver tissue L-MDA, superoxide dismutase (SOD), catalase (CAT) and reduced glutathione $(\mathrm{GSH})$ were determined according to the method adapted by Ohkawa et al., (1979), Nishikimi et al., (1972), Aebi, (1984) and Beutler et al., (1963), respectively.

\subsubsection{Molecular analysis:}

Total RNA was isolated from liver tissue of rats using RNeasy Mini Kit (Thermo Scientific, Fermentas, \#K0731) according to the manufacturer's protocol. Following determination of RNA concentration and purity by Quawell nanodrop Q5000 (USA), 5 $\mathrm{mg}$ of total RNA from each sample was reverse transcribed using Quantiscript reverse transcriptase. The produced cDNA was used as a template to determine the relative expression of TNF- $\alpha$ gene using StepOnePlus real time PCR system (Applied Biosystem, USA) and gene specific primers. The reference gene, $\beta$ actin, was used to calculate fold change in target genes expression. The thermal cycling conditions, melting curves temperatures, and calculation of relative expression was done. For the treated groups, assessment of $2^{-\Delta \Delta \mathrm{Ct}}$ determined the fold change in gene expression relative to the control.

Forward and reverse primers sequence for real time PCR.
Gene $\quad$ Forward primer

('5 ------'3)
Reverse primer

('5 -----' 3$)$

$T N F-a$

TCATACCAGGGCTTGAGCTCA

$\beta$-actin AAGTCCCTCACCCTCCCAAAAG

\subsection{Statistical analysis:}

The results were expressed as mean \pm SE using SAS computerized program v. 9.2 (SAS, 2008) program to calculate the analysis of variance. The data were analyzed using one-way ANOVA to determine the

\section{RESULTS}

The qPCR results revealed a significant up-regulation of TNF- $\alpha$ gene expression level in livers of mycotoxin rats as compared to control group (Table 1). This expression was significantly down-regulated following treatment by moringa.

The obtained results presented in table (2) revealed that, the mean values of liver GSH concentration was significantly decreased in mycotoxin statistical significance of differences among groups. Duncan's test was used for making a multiple comparisons among the groups for testing the inter-grouping homogeneity. Values were considered statistically significant when $\mathrm{p}<0.05$.

group in comparison with control group. Pretreatment with moringa in group (3) significantly increased serum GSH concentration in comparison with mycotoxin group.

The mean values of liver SOD and CAT activities were significantly increased in mycotoxin group in comparison with control group. Pretreatment with moringa group (3) significantly decreased liver SOD and CAT activities when compared with mycotoxin treated rats only. 
Exposure of mycotoxin via food to normal rats caused significant increase in the value of liver L-MDA concentration in comparison with control group. Pretreatment with moringa group (3) caused nonsignificant decrease in liver L-MDA concentration.

Table (1): Changes in relative expression of TNF- $\alpha$ gene in liver tissues of mycotoxin -intoxicated rats after moringa treatment.

\begin{tabular}{lc} 
Animal groups & TNF- $\alpha$ (Fold chang \\
\hline Group I: & $1.00^{\mathrm{d}} \pm 0.08$ \\
Normal control & \\
Group II: & $5.24^{\mathrm{a}} \pm 0.25$ \\
$\begin{array}{l}\text { Mycotoxin group } \\
\text { Group III: }\end{array}$ & \\
Mycotoxin + Moringa group & $3.76^{\mathrm{b}} \pm 0.12$ \\
\hline
\end{tabular}

Mean values with different superscript letters in the same column are significantly different at $(\mathrm{P} \leq 0.05)$. $(\mathrm{n}=3)$ in each group.

Table (2): Effects of moringa against mycotoxins induced changes on tissue GSH, SOD, Catalase and L-MDA in male rats.

\begin{tabular}{|c|c|c|c|}
\hline Parameter & Control group & Mycotoxin group & Mycotoxin + Moringa group \\
\hline GSH( ng/g.tissue) & $4.882 \pm 0.27^{\mathrm{a}}$ & $2.67 \pm 0.20^{\mathrm{c}}$ & $4.04 \pm 0.24^{b}$ \\
\hline $\mathrm{SOD}(\mathrm{u} / \mathrm{g}$.tissue $)$ & $29.04 \pm 2.64^{c}$ & $57.63 \pm 7.26^{\mathrm{a}}$ & $25.25 \pm 1.92^{c}$ \\
\hline Catalase(u/g.tissue) & $1.11 \pm 0.04^{\mathrm{b}}$ & $1.37 \pm 0.06^{\mathrm{a}}$ & $1.1 \pm 0.12^{b}$ \\
\hline L-MDA(nmol/g.tissue) & $3.36 \pm 0.21^{\mathrm{c}}$ & $6.44 \pm 0.37^{\mathrm{a}}$ & $5.8 \pm 0.32^{a b}$ \\
\hline
\end{tabular}

Data are prese

nted as means \pm Standard Error (S.E)

Means values with different superscript letters in the same row are significantly different at $(\mathrm{P}<0.05)$. $(\mathrm{n}=5)$ in each group.

\section{DISCUSSION}

Mycotoxin is a secondary toxic metabolite that is produced from a mycotoxic mould. A mould species can produce several types of mycotoxin. Therefore, any mouldy sample may contain numerous mould species; it may be contaminated with different mycotoxins (Abdelhamid et al., 2004).
Moringa oleifera is a good source of aminoacids, it contains a number of important minerals, $\beta$-carotene, various phenolics and vitamins (Siddhuraju and Becker, 2003). Moringa shows strong inhibition for Aspergillus niger and Aspergillus oryzae, Aspergillus nidulans and Aspergillus terreus 
(Prashith et al., 2010). Moringa leaves extract showed potent effect against liver damage in rats (Ezejindu et al., 2014).

The obtained qPCR results revealed a significant up-regulation of TNF- $\alpha$ gene expression level in livers of mycotoxin treated rats as compared to control group. These results are nearly similar with the recorded data of Sharma et al., (2005) who investigated that, FB1 induced apoptosis in mice primary hepatocytes which responsible TNF- $\alpha$ production. Indeed, Barton et al., (2001) stated that, TNF- $\alpha$ plays a causal role in the development of aflatoxin B1 hepatotoxicity in rats. Alleviation of serum TNF- $\alpha$ levels produced in intoxicated rats may be attributed to their ant-inflammatory and antitumor activities. The expression of TNF- $\alpha$ gene was significantly down-regulated following treatment by moringa. This suggestion was supported the findings of Hörl, (2010) who recorded that, moringa leaves extract also extensively inhibit the inflammatory cascade by effectual modulation of inflammatory cytokines(TNF- $\alpha$ ), thus curbing the further exacerbation of mycotoxin renal injury mediated by inflammatory cytokines. These features evidently project moringa leaves extract as a successful hepatorenal protective agent. There is an evidence indicated that some components of moringa such as Vitamin $\mathrm{C}$ and B- carotene have antimutagenic effect against toxicants. Also vitamin $\mathrm{C}$ was known to be immune system booster and reduces the free radicals in the body (Abdou et al., 2012).

The results of the current study revealed that, the main value of liver reduced glutathione (GSH) concentration was significantly decreased in mycotoxin group in comparison with control group. These results are in a harmony with those of Mobio et al., (2003) who concluded that, induction by FB1 in rats lead to apoptosis in different cell types which is considered to be a common result of oxidative stress caused by ROS production and subsequent reduction of intracellular GSH levels. Similarly, Jagetia et al., (2004) observed that, decreased GSH levels might be due to increased utilization in protecting ' $\mathrm{SH}$ ' containing proteins from lipid peroxides. Pretreatment with moringa group significantly increased serum GSH concentration in comparison with mycotoxin group. These results are nearly similar with Ibrahim et al., (2018) who concluded that, the treatments by moringa together with AFB1 slightly significantly ameliorated the adverse effects of AFB1-induced toxicity, such that MDA was decreased but GSH was increased.

The results of the current study revealed that, mycotoxin treated rats significantly increased liver superoxide dismutase SOD and catalase CAT activities in comparison with control group. These results came in accordance with the recorded data of Abdel-Wahhab et al., (2010) who provided that, the mechanisms of mycotoxins induced liver injury have demonstrated that SOD and CAT play an important role in the detoxification of the reactive and toxic metabolites of this mycotoxin, and that the liver necrosis begins when the glutathione stores are almost exhausted. Pretreatment with moringa significantly decreased liver SOD and CAT activities when compared with mycotoxin treated rats only. Similarly, Ibrahim et al., (2018) proved that, activities of SOD and CAT were decreased significantly under the induction of AFB1which induced genotoxicity and biochemical alterations in rats. moringa treatments stimulated again both enzymes relative to intoxicated control, either with or without AFB1 ingestion. The continuous treatments by moringa without AFB1 induction resulted in more improvements in the both activities.

The recorded data showed significant increase in the value of liver tissue L-MDA concentration in mycotoxins treated rats when compared with normal 
control group. These results are agreed well with those of Meki et al., (2004) who reported that the increased LP level with the concomitant decrease in antioxidant enzyme activities were the most pronounced markers for AFB 1 toxicity and carcinogenicity. Also, Nanjappaiah and Hugar, (2012) found that, significant elevation of MDA in rats treated with toxin as compared to negative controls. A non-significant decrease in liver L-MDA concentration was observed in moringa pretreatment mycotoxin treated group in comparison with mycotoxin rats only. Furthermore, Hasnaa et al., (2015) showed that, the used doses of Moringa extract (1.3, 2.0, 2.6 and $4.0 \mathrm{gm} / \mathrm{Kg}$ ) as a protective agent significantly reversed the intoxicated elevation of hepatic MDA level in rats. The reduction of MDA level was increased by increasing the dose level.

\section{CONCLUSION}

Moringa contains protective factors used in curing of oxidative stress and liver damage induced by mycotoxins in rats. The treatment of animals exposed to mycotoxins with Moringa significantly ameliorated liver lipid peroxidation and antioxidant enzyme activities.

\section{REFERENCES}

Abdelhamid,A.M.,Abdel Khalek.A.E., Mehrm, A.I. and Khalil, F.F. 2004.An attempt to alleviate aflatoxicosis on Nile tilapia fish by dietary supplementations with chicken, hatchery by, products (egg shells) and shrimp processing wastes (shrimp shells) . 1, On fish performance and feed and nutrients utilization. J. Agric.Sci.Mansoura Univ., 29:6157, 6173.

Abdel-Wahhab, M.A. , Hassan, N.S. , ElKady, A.A. , Khadrawy, Y.A. , ElNekeety, A.A. , Mohamed, S.R. , Sharaf, H.A. and Mannaa, F.A. 2010. Red ginseng extract protects against aflatoxin B 1 and fumonisins-induced hepatic pre-cancerous lesions in rats, Food Chem. Toxicol. 48 (2) 733-74

Abdou, H. S., Salah, S. H., Booles, H. F. and Abdel Rahim, E. A. 2012.Antioxidant effect of celery against carbontetrachloride induced hepatic damage in rats. African Journal of Microbiology Research , 6 (27):56575667.

Aebi, H.1984. Catalase in vitro, Methods Enzymol 105, 121-126.

Al-Malki, A.L. and El Rabey, H.A. 2015. The antidiabetic effect of low doses of Moringa oleifera Lam. seeds on streptozotocin induced diabetes and diabetic nephropathy in male rats. Biomed.Res.Int.pp.1-13.

Anwar, F.,Latif, S., Ashraf, M. and Gilani, A.H. 2007.Moringa oleifera: A food plant with multiple medicinal uses. Phytother Res 21: 17-25.

Barton, C.C., Barton, E.X., Ganey, P.E., Kunkel, S.L. and Roth, R.A. 2001.Bacterial lipopolysaccharide enhance aflatoxin B1 hepatotoxicity in rats by a mechanism that depends on tumor necrosis factor alpha. Hepatology 2001; 33: 66-73.

Bennett, R.N., Mellon, F.A. and Foidl, N. 2003, Profiling glucosinolates and phenolics in vegetative and reproductive tissues of the multi-purpose trees Moringa oleifera L. (Horseradish tree) and Moringa stenopetala L. J Agric Food Chem 51: 3546-3553.

Beutler, E., Duron, O. and Kelly, M.B. 1963. Improved method for the determination of blood glutathione, J. Lab Clin. Med. 61:882-88.

Blout, W. P. 1961. Turkey "X" disease. Turkeys 9:52, 55-58, 61, 77.

Caceres, A., Cabrera, O., Morales, P., Mollined and Media, $P$. 1992.Pharmaceutical properties of M. oleifera. Preliminary screening for 
antimicrobial

activity.

J.Ethnopharmacol. 36:233-237.

Darwish, H.R., Omara, E.A., Abdel-Aziz, K.B., Farag, I.M., Nada, S.A.,Tawfek, N.S., 2011.Saccharomyces cerevisiae modulates aflatoxin- induced toxicity in male Albino mice. Report and Opinion 3(12): 32-43.

Dönmez, N., Dönmez, H.H., Keskin, E., Kisadere, I., 2012. Effects of Aflatoxin on Some Haematological Parameters and Protective Effectiveness of Esterified Glucomannan in Merino Rams. Scientific World J 2012: 1-4.

Eshak, M.G., Osman, H.F., 2013. Role of Moringa oleifera leaves on biochemical and genetical alterations in irradiated male rats. Middle East J Sci Res 16(10): 1303-1315.

Ezejindu, D.N. Udemezue, O.O. and Chinweife, K.C. 2014. Hepatoprtective effects of Moringa oleifera extract on liver of wistar rats. Int $\mathrm{J}$ Res Med Health Sci; 3(5): 23-7.

Fahey, J.W., Dinkova-Kostova, A.T., Talalay, P.,2004. The "Prochaska" microtiter plate bioassay $\mathrm{V}$ for inducers of NQ01. Chapter 14 in Methods in Enzymology, (Eds.) H. Sies \& L. Packer, Elsevier Science 382(B):, San Diego, CA, pp 243-258.

Hasnaa, A. R., Inas, S. G. , Ibrahim, M. F.and

Ezzo, M.2015. Protective and Therapeutic Effect of Moringa oleifera Leaf Extract on DNA Damage, Cytogenetic Changes, Sperm Abnormalities and High Level of MDA Induced by CCL4 in Rats. RJPBCS 6(1) Page No. 1061.

Hörl, W.H.2010.Nonsteroidal antiinflammatory drugs and the kidney .Pharmaceuticals 3 :2291-2321

Ibrahim, M. F., Hanaa, M. R. , Hasnaa, A. R., Inas, S. G., Sherifa, H. S., Emam, A. A. and

Aboelfetoh,

M.

A.2018.Ameliorative role of ethanolic extract of Moringa oleifera leaf on aflatoxin B1-induced genotoxicity and biochemical alterations in rats. J Arab Soc Med Res 13:60-70

Jagetia, G.C., Reddy, T.K. and Kedlaya, R. 2004. Influence of naringin on ferric iron induced oxidative damage in vitro, Clin Chim Acta, , 347, 189-197.

Jaiswal, D., Kumar, R., Kumar, A., Mehta, S. and Watal, G. 2009. Effect of Moringa oleifera lam. leaves aqueous extract therapy on hyperglycemic rats. J. Ethnopha. 123(3):392-396.

Krishnamurthy, P.T., Vardarajalu, A., Wadhwani, A. and Patel, V. 2015. Identification and characterization of a potent anticancer fraction from the leaf extracts of Moringa oleifera L.Indian J. Exp. Biol. 53(2):98-103.

Meki, A.R., Esmail, El-D., Hussein, A.A., Hassanein, H.M. 2004. Caspase-3 and heat shock protein-70 in rat liver treated with aflatoxin B1: effectof melatonin. Toxicon43: $93-100$

Minaiyan, M., Asghari, G., Taheri, D., Saeidi, M. and Nasr-Esfahani, S. 2014. Antiinflammatory effect of Moringa oleifera Lam. seeds on acetic acid-induced acute colitis in rats. Avicenna J. Phytomed. 4(2):127-136.

Mobio, T.A., Tavan, E., Baudrimont, I., Anane, R., Carratū, M.R., Sanni, A., Gbeassor, M.F., Shier, T.W., Narbonne, J.-F. and Creppy, E.E.2003. Comparative study of the toxic effects of fumonisin B1 in rat C6 glioma cells and p53-null mouse embryo fibroblasts. Toxicology, 183, 65-75.

Nanjappaiah, H. M. and Hugar, S. 2012. Prophylactic and curative effects of Moringa oleifera Lam. Pods in CCl4 damaged rat liver, Indian Journal of 
Natural Products and Resources, 3(4) : 541-546.

Nishikimi, M., Roa, N.A. and Yogi, K. 1972. Measurement of superoxide dismutase Biochem. Bioph. Res. Common., 46, $849-854$.

Ohkawa, H., Ohishi, W. and Yagi, K. 1979. Assay for lipid peroxides in animal tissues by thiobarbituric acid reaction.Anal Biochem 95(2):351-8.

Overy, D.P., Seifert, K.A., Savard, M.E. and Frisvad, J.C. 2003. Spoilage fungi and their mycotoxins in commercially marketed chestnuts. Int $\mathrm{J}$ Food Microbiol 88: 69-77.

Prashith Kekuda, T.R., Shobha, K.S. and Onkarappa, R. 2010. Studies on antioxidant and anthelmintic activity of two Streptomyces species isolated from Western Ghat soils of Agumbe Karnataka. J Pharm Res; 3: 26-9.

Saalu, L.C., Ogunlade, B., Ajayi, G.O., Oyewopo, A.O. ,Akunna, G.G., Ogunmodede, O.S. 2012. The hepatoprotective potentials of Moringa oleifera leaf extract on alcohol-induced hepatotoxicity in wistar rat. american journal biotechnology and molecular sciences ISSN Print: 2159-3698.

SAS . 2008. Statistical analysis system : User's guide v. 9.2, Inst. Inc., Cary N.C., USA.

Sharma, N., Suzuki, H., He, Q. and Sharma, R.P. 2005. Tumor necrosis factor $\alpha-$ mediated activation of c-Jun NH2terminal kinase as a mechanism for fumonisin B1 induced apoptosis in murine primary hepatocytes. J Biochem. Molecular Toxicology, 19 (6):359-367.

Siddhuraju, P. and Becker, K. 2003. Antioxidant properties of various solvent extracts of total phenolic constituents from three different agroclimatic origins of drumstick tree
(Moringa oleifera Lam.). J Agric Food Chem 15: 2144-2155.

Souravh, B., Guru, S. S. and Ramica, S. 2014. Antiobesity and hypolipidemic activity of Moringa oleifera leaves against high fat diet-induced obesity in rats. Advances in Biology, pp.1-9.

Vongsak, B., Sithisarn, P., Mangmool, S., Thongpraditchote, S., Wongkrajang, Y. and Gritsanapan, W. 2013. Maximizing total phenolics, total flavonoids contents and antioxidant activity of Moringa oleifera leaf extract by the appropriate extraction method. Ind Crops Prod; 44: 566-71

World Health Organization, WHO 2002. Report on Meetings of Expert Committees and Study GroupsEvaluation of Certain Mycotoxins. Geneva:World Health Organization.

Yaman, T., Yener, Z., Celik, I., 2016. Histopathological and biochemical investigations of protective role of honey in rats with experimental aflatoxicosis. BMC Complement Altern Med 16:232.

Yang, Y., He, S., Wang, Q., Li, F., Kwak, M.J., Chen, S., O'Connell, D., Zhang, T., Pirooz, S.D., Jeon, Y., Chimge, N.O., Frenkel, B., Choi, Y., Aldrovandi, G.M., Oh, B.H., Yuan, Z., Liang, C., 2016. Autophagic UVRAG promotes UV-induced photolesion repair by activation of the CRL4 (DDB2) E3 ligase. Mol Cell 62(4): 507-519. 